\title{
A causal modelling framework for the simulation and explanation of the behaviour of structures
}

\section{Paolo Salvaneschi, Mauro Cadei, Marco Lazzari}

\author{
ISMES, Via Pastrengo 9 Seriate, Bergamo, Italy
}

\section{Abstract}

An approach to the modelling of systems in civil engineering is presented. It allows the integration of quantitative relations in a qualitative causal framework which uses objects and Petri nets to represent the device and process ontologies. This approach supports the modelling and simulation of the behaviour of a physical system and causal explanations of it. The explanations are customisable depending on the needs of different users. The approach is shown by modelling the seismic behaviour of a masonry building, simulating it and generating causal explanations tailored for the needs of different users. An example application is presented through IGOR, a decision support system for seismic assessment of buildings and planning of precautionary operations.

Key words: qualitative models, causal models, qualitative/quantitative knowledge integration, explanation, seismic engineering.

\section{INTRODUCTION}

Much of the knowledge employed by engineers is of a qualitative nature. Every day they deal with quantitative entities such as equations and numbers, but qualitative reasoning is crucial for comprehending problems. planning for solving them, identifying suitable quantitative relations and interpreting the results of quantitative computations [1].

There has been great effort, in the past, in formalising quantitative reasoning, so that there are programs supporting engineers in the quantitative aspects of their activity, but other work has still to be done in the formal representation of qualitative aspects of engineering problem solving [2]. The aim of the research in this field is the formalisation of those qualitative aspects so that computer systems can be developed to support qualitative reasoning. [1] Moreover, existing approaches bridge the methodologies in the field of artificial intelligence and in the field of simulation. They introduce methodologies and formalisms for developing multiple, cooperative models derived from qualitative physics [3]. 
Excerpt from: Mauro Cadei, Marco Lazzari, Paolo Salvaneschi, "A causal modelling framework for the simulation and explanation of the behaviour of structures", Artificial Intelligence in

Engineering, 11(3), 1997, 205-216. DOI:10.1016/S0954-1810(96)00040-4

Copyright @ 1997 Published by Elsevier Science Ltd.

In the field of seismic engineering, several researchers have taken advantage of qualitative techniques to model the seismic behaviour of buildings. For example Miyasato et al. [4], Ishizuka et al. [5] and Pagnoni et al. [6] modelled the knowledge in form of a tree of factors to evaluate the seismic vulnerability, while Zhang and Yao [7] used conceptual networks and frames to map data into damage states and Bozzo and Fenvesg introduced a qualitative reasoning methodology to support the preliminary design of earthquake resistant buildings,

In particular, qualitative causal analysis is very important in an engineer's problem solving. The need for the prediction and causal explanation of the expected behaviour of a system and, in engineering in particular, of an artifact is common in many domains. For example. a simulation activated by critical inputs can allow the detection of the weakest components of the modelled system in order to plan precautionary operations on them for preventing possible failures and damage.

\section{THE PROBLEM}

The paper describes an approach to the integration of quantitative relations in a qualitative Causal framework. This supports the modelling and simulation of the behaviour of a physical system and causal explanations of it. The explanations are customisable depending on the needs of different users.

An example of the application of this approach is IGOR (Fig. 1), a decision support system that helps technicians seismically assess buildings and plan pre- cautionary operations on them. The approach and the work done were initially related to the problem of...

$[\ldots]$

\section{CONCLUSIONS}

The modelling framework has been used to implement several models. The main result is the availability of tools which allow easy implementation of models at various levels of abstraction, which may exploit both quantitative and qualitative knowledge.

The IGOR system, which applied those tools to the seismic risk evaluation of buildings, provides a powerful support to engineers which was not available before. They may define a suitable strategy for assessing the seismic risk of an urban nucleus and IGOR will support them to store the data collected, simulate the behaviour using various models, explain the behaviour and simulate possible strengthening actions. 
Excerpt from: Mauro Cadei, Marco Lazzari, Paolo Salvaneschi, "A causal modelling framework for the simulation and explanation of the behaviour of structures", Artificial Intelligence in Engineering, 11(3), 1997, 205-216. DOI:10.1016/S0954-1810(96)00040-4 Copyright ( 1997 Published by Elsevier Science Ltd.

\section{REFERENCES}

[1] I. Weld, D. S. de Kleef, J. Qualitative physics: a personal view. Readings in Qualitative Reasoning About Physical Systems, ed. D. S. Weld \& J. de Kleef, Morgan Kaufmann, San Mateo, CA, 1990, 2.

[2] Weld, D. S. de Kleef, J. Causal explanations of behaviour. In Readings in Qualitative Reasoning About Physical Systems, ed. D. S. Weld \& J. Kleer. Morgan Kaufmann, San Mateo, CA 1990, 611-16.

[3] Fishwick, P. A. Zeigler, B. P., A multimodal methodology for qualitative model engineering. ACM Transactíons on Modelling and Computer Simulation, 1992, 2(1), 5281.

[4] Miyasato, G. H.. Dong, W. M., Levitt, R. E., Boissonnade, A. C. \& Shah, H. C. Seismic risk analysis system. In Expert Systems in Civil Engineering, ed. C. N. Kostem \& M. L, Maher. ASCE, New York, 1986.

[5] Ishizuka, M., Fu, K. S. Yao, J. T. P. SPERIL I - Computer based structural damage assessment system. Technical Report. School of Civil Engineering, Purdue University, West Lafayette. IND, 1981.

[6] Pagnoni, T., Tazir, Z. H. Gavarini, C. AMADEUS: a KBS for the assessment of earthquake damaged buildings. Proc. IABSE Colloquium on Expert Systems in Civil Engineering. International Association for Bridge and Structural Engineering, Zürich, Switzerland, 1989, 219-28.

[7] Zhang, X. J. Yao. J. T. P. Automation of knowledge organization and acquisition. Microcomp. Civ. Engng., 1988, 3, I-12.

[8] Bozzo, L. M. Fenves. G. L. Qualitative reasoning about seismic behavior of buildings. Proc. Tenth World Conference on Earthquake Engineering. A. A. Balkema, Rotterdam, 1992, 6291-6.

[9] Forbus, K. D., Qualitative physics: past, present and future. In Exploring Artificial Intelligence, ed. H. Shrobe. Morgan Kaufmann, San Mateo, CA, 1988, pp.239-96.

[10] Forbus, K. D., Qualitative process theory. Artificial Intelligence, 1984. 24, 85-168.

[11] Petri, C. A., General net theory. Proceedings of the Joint IBM - University of Newcastle upon Tyne Seminar, 1976, 131-69.

[12] Petri, C. A. Interpretation of net theory. Internal Report, Gesellschaft für Mathematik und Datenverarbeitung, Bonn, 1975. 
Excerpt from: Mauro Cadei, Marco Lazzari, Paolo Salvaneschi, "A causal modelling framework for the simulation and explanation of the behaviour of structures", Artificial Intelligence in

Engineering, 11(3), 1997, 205-216. DOI:10.1016/S0954-1810(96)00040-4

Copyright (@ 1997 Published by Elsevier Science Ltd.

[13] de Kleef. J. The origin and resolution of ambiguities in causal arguments.

Proceedings IJCAI '79, Tokyo, Japan, 1979, 197-203.

[14] Wick, M. R. Thompson, W. B. Re-constructive expert systems explanation. Artificial Intelligence, 1992. 54(1-2), 33-70.

[15] Torasso, P. Console, L. Diagnostic Problem Solving. Combining Heuristic, Approximate and Causal Reasoning. North Oxford Academic. 1989.

[16] Wallis, J. W. Shortlifie, E. H. Customized explanations using causal knowledge. Rule-Based Expert Systems. ed. B. G. Buchanan \& E. H. Shortliffe. Addison-Wesley. Reading, MA, 1984. 371-88.

[17] Paulay, T. Priestley. M. J. N. Seismic Design of Reinforced Cancrete and Masonry Buildings. John Wiley, New York, 1992.

[18] Salvaneschi, P., Cadei. M., Calvi, G. M. \& Rossi. P. Towards a knowledge-based system for seismic assessment of buildings. Microcomp. Civ. Eng. 1990, 5(1), 29-41.

[19] Salvaneschi P., Cadei. M., Lazzari M. Applying A.I. to structural safety monitoring and evaluation. IEEE Expert 1996, 11(4), 24-34.

[20] Benedetti, D., Benzoni, G. Parisi, M. A. Seismic vulnerability and risk evaluation for old urban nuclei. J. Inl. Assoc. Earth. Eng. 1988, 16(2).

[21] Cadei, M., Panzeri, P., Peano, A. \& Salvaneschi. P, A mobile laboratory with an expert system for seismic assessment of buildings. Proc. the Tenth World Conference on Earthquake Elzgirzeering. A. A. Ba1kema, Rotterdam, 1992, 6311-16.

[22] ISMES, Progettazione di un laboratorio mobile per la valutazione della adeguatezza antisismica degli edifici - Relazione tecnica relativa al terzo anno della ricerca, ISMES RAT-DMM-1003/93, 1993.

[23] Environment project EVSV-CT93-0305, Earthquake protection for historic town centres (TOSQA). Task 2: Case studies. Task Report: Survey Data Analysis and Comparative Assessment, 1996.

[24] Environment project EV5V-CT93-0305, Earthquake Protection for Historic Town Centres (TOSQA), Task 5: Develop Vulnerability Methods and Propose Strategies for Retrofitting. Task Report: Adapt Vulnerability Methods examined by IGOR to incorporate Retroñt, 1996.

[25] Chandrasekaran, B., Tanner, M. C. Josephson, J. R. Explanation: the Role of Control Strategies and Deep Models, Expert Systems: the User Interface. Ablex, Norwood. NJ, 1987, 219-47. 